\title{
Occurrence of Aggregatibacter actinomycetemcomitans in Brazilians with chronic periodontitis
}

\section{José Roberto Cortelli(a) Caio Vinícius Gonçalves Roman- Torres $^{(b)}$ \\ Davi Romeiro Aquino(a) \\ Gilson Cesar Nobre Franco(c) \\ Fernando Oliveira Costa ${ }^{(d)}$ \\ Sheila Cavalca Cortelli(a)}

(a) $\mathrm{PhD}$, Professor; (b) PhD - Department of Periodontology, University of Taubaté, SP, Brazil.

(c) $\mathrm{PhD}$, Professor, Department of Oral Biology, University of Taubaté, SP, Brazil.

(d) PhD, Professor, Department of Periodontology, Federal University of Minas Gerais, MG, Brazil.

Corresponding author:

José Roberto Cortelli

Rua Expedicionário Ernesto Pereira, 110 - Centro

Taubaté - SP - Brazil

CEP: 12020-330

Email: ircortelli@uol.com.br

Received for publication on Jan 04, 2010 Accepted for publication on Apr 16, 2010

\begin{abstract}
Studies have suggested that $A$. actinomycetemcomitans is involved in the aetiology of aggressive periodontitis as well as in chronic periodontitis. This study was aimed at elucidating the occurrence of $A$. actinomycetemcomitans in a Brazilian population with chronic periodontitis. A total of 555 (mean age $33.04 \pm 12.45$ ) individuals, living in two large areas of the São Paulo State, namely "Baixada Santista" and "Vale do Paraíba", and diagnosed with mild [180 (mean age 29.59 \pm 10.94 )], moderate $[241$ (mean age $31.18 \pm 11.45$ )] or severe [134 (mean age $33.04 \pm 12.45)$ ] chronic periodontitis were enrolled in this survey. Clinical exams including measurements of Probing Depth, Clinical Attachment Loss, Plaque and Gingival indices and subgingival microbiological assessments were performed at all population. The genomic DNA of $A$. actinomycetemcomitans was identified by Polymerase Chain Reaction from periodontal pocket samples. The occurrence of A. actinomycetemcomitans among chronic periodontitis subjects as well as its association with age and gender were statistically analysed using the Chi-square and Odds Ratio tests. The significance of differences was established at 5\% $(p<0.05)$. A. actinomycetemcomitans was detected in $102(18.37 \%)$ individuals: 29 (16.11\%) mild; 42 (17.42\%) moderate; and 31 (23.13\%) severe chronic periodontitis with no statistical difference among groups. A higher occurrence of the searched bacterium was found both in the youngest group $(p<0.05)$ as well as in the female group $(p<0.05)$. This study elucidated that $A$. actinomycetemcomitans harbored subgingival pockets of our target group of chronic periodontitis subjects and that this bacterium seems to be inversely related to age, but related to the female gender.
\end{abstract}

Descriptors: Actinobacillus actinomycetemcomitans; Prevalence; Chronic periodontitis.

\section{Introduction}

Aggregatibacter actinomycetemcomitans (A. actinomycetemcomitans), previously described as Actinobacillus actinomycetemcomitans, is a Gram-negative, facultative non motile rod, anaerobic and commensal bacterium associated with infections in the oral cavity. ${ }^{1}$ Despite the rather common presence of the organism in the oral cavity, a literature review for nonoral $A$. actinomycetemcomitans infections revealed that less than 200 cases were reported during the last 30 years. $^{2}$ 
Particularly, in the oral cavity A. actinomycetemcomitans has been strongly associated with aggressive periodontitis in several epidemiological studies, however, less investigated in chronic periodontitis patients. ${ }^{3-10}$

This bacterium expresses several putative virulence factors which enable it to colonize the oral cavity, invade periodontal tissues and evade host defenses. ${ }^{11}$ Additionally, different serotypes of A. actinomycetemcomitans have been shown to be associated with periodontal health and disease. ${ }^{12,13}$

Chronic periodontitis may begin in adolescence as a slowly progressing disease that becomes clinically significant in the mid-30 s and continues throughout life. The prevalence of mild to moderate forms of chronic periodontitis could reach $60 \%$ of the worldwide population. On the other hand, severe forms are observed in 10 to $15 \%$ of the global population. ${ }^{8,14,15}$

Microbiological studies have identified only a few bacterial species associated with periodontal disease in adults. ${ }^{16}$ The American Academy of Periodontology ${ }^{17}$ (1996), designated A. actinomycetemcomitans as one of the periodontal pathogens functioning as an etiological agent of periodontitis.

As studies worldwide stressed the prevalence of A. actinomycetemcomitans in aggressive periodontitis, this study was aimed at verifying the occurrence of this bacterium in a Brazilian population with chronic periodontitis living in São Paulo State.

\section{Materials and Methods}

Participants included in the present cross-sectional study were recruited from 2 areas of the São Paulo State. One area designed "Baixada Santista", which represents a metropolitan area on the coast of the São Paulo State. The other one namely "Vale do Paraíba”, located in the eastern part of the São Paulo State. The study population was defined as a typical convenience sample, because all the selected patients were individuals who looked for periodontal treatment in a Public Health Center, Dental Clinic at Cubatão-SP-Brazil and in the Department of Periodontics-University of Taubate at TaubateSP-Brazil.

Potential subjects were screened for inclusion and exclusion criteria. To be included in the study the subjects had to be in good general medical health and have at least 14 natural teeth. Individuals were excluded if they had the following conditions (i) any condition requiring antibiotic prophylaxis for dental exam, (ii) uncontrolled systemic diseases, (iii) immunological compromise, (iv) pregnancy or women currently breast-feeding, (v) periodontal treatment 12 months before the beginning of the study, (vi) antibiotic treatment within 6 months prior to the clinical and microbial examination (vii) diagnosed gingivitis or aggressive periodontitis.

The current study was approved by the Institutional Committee on Research Involving Human Subjects of the University of Taubate.

\section{Clinical procedures}

Two trained and calibrated examiners (by Probing Depth $\{\mathrm{PD}\}$ and Clinical Attachment Loss $\{C A L\})$ conducted all clinical measurements and collected the microbial samples. Intra- and inter-examiners agreement was high (kappa $=0.84$ for PD and 0.82 for $\mathrm{CAL}$ ). The reproducibility of the interexaminers measurements was recalculated after 6 months of the beginning of the study.

The clinical measurements were used to establish the diagnosis of chronic periodontitis. The population received a full-mouth examination to assess the Plaque and Gingival indices. ${ }^{18}$ In addition, Probing Depth and Clinical Attachment Loss (CAL) were measured on 6 surfaces of all present teeth using a manual periodontal probe (PCPUNC 15 Hu-Friedy Mfg. Co., Inc., Chicago, IL).

The study population was placed into 3 groups based on their average full-mouth CAL measurements. ${ }^{19}$ All CAL measurements were made in millimeters, rounded down to the nearest whole millimeter. These 3 groups and their categorization were:

- Mild Periodontitis: Mean CAL $\geq 0.6 \mathrm{~mm}$ to $1.5 \mathrm{~mm}$, no interproximal sites with CAL $\geq 3 \mathrm{~mm}$. No more than 3 missing teeth with the exception of extracted third molars, teeth extracted for orthodontic reasons, teeth lost as a result of extraoral trauma or extensive decay, or teeth that were congenitally missing.

- Moderate Periodontitis: Mean CAL $\geq 1.6 \mathrm{~mm}$ 
to $2.4 \mathrm{~mm}$ and $\leq 8$ sites with interproximal $\mathrm{CAL} \geq 3 \mathrm{~mm}$ distributed through at least 3 quadrants or at least 6 teeth. No more than 5 missing teeth with the exception of extracted third molars, teeth extracted for orthodontic reasons, teeth lost as a result of extraoral trauma or extensive decay, or teeth that were congenitally missing.

- Severe Periodontitis: Mean CAL $\geq 2.5 \mathrm{~mm}$ and 1 or more sites in 3 out of 4 quadrants with interproximal CAL measurements of $\geq 5 \mathrm{~mm}$. No more than 14 missing teeth with the exception of extracted third molars, teeth extracted for orthodontic reasons, teeth lost as a result of extraoral trauma or extensive decay, or teeth that were congenitally missing.

\section{Microbial sampling and laboratory procedures}

A pooled subgingival sample was collected from each subject (555 subjects), from the first molars and incisors using sterile paper points (Tanari \#30, Tanariman Industrial Ltda., Manacapuru, AM, Brazil) inserted to the depth of the gingival sulcus after removal of supragingival plaque. For subjects missing those teeth, microbial samples were obtained from second molars and/or lateral incisors.

After being placed in the gingival sulcus for 60 seconds, paper points were removed and transferred into a microtube containing reduced Ringer's solution $(1 \mathrm{ml}$ ) (Oxoid Ltd., Basingstoke, Hampshire, United Kingdom). The bacterial cells in the microtube were dispersed using a vortex (PRO Scientific Inc., Oxford, UK) mixer at maximal setting for $1 \mathrm{~min}$ and then maintained at $-80^{\circ} \mathrm{C}$ until laboratory processing. The presence of A. actinomycetemcomitans was determined by polymerase chain reaction (PCR), as described below.

The subgingival samples in the microtube were dispersed using a Vortex and centrifuged (3 minutes at $12,000 \mathrm{rpm})$. From the cellular bacteria pellet, genomic DNA was extracted using a commercial DNA purification Kit $\left(\right.$ InstaGene ${ }^{\circledR}$, Bio-Rad laboratories, Hercules, CA, USA), according to the manufacturer's instructions.

The PCR method (Thermalcycler-Perkin El- mer Cetus, Wellesley, MA, USA) was performed according to the protocol described by Cortelli et al. ${ }^{20}$ (2009), using specific primers for A. actinomycetemcomitans. $^{21}$

\section{Statistical analysis}

The frequencies of $A$. actinomycetemcomitans among mild, moderate and severe periodontitis subjects were analysed using the Chi-square and Odds Ratio tests. The significance of differences was established at $5 \%(p<0.05)$. All tests were performed using statistical software (Biostat 5.0 and SPSS 15.0 for Windows Release 15.0, Chicago, IL-USA).

\section{Results}

We enrolled a total of 555 subjects (mean age $33.04 \pm 12.45$ ) with mild, moderate or severe periodontitis. Out of 555 subjects, 180 (mean age $29.59 \pm 10.94$ years) were considered to have mild chronic periodontitis; 241 (mean age $31.18 \pm 11.45$ ) were diagnosed as moderate chronic periodontitis; while 134 (mean age $33.04 \pm 12.45$ ) were considered to have severe chronic periodontitis.

Out of 555 subjects, A. actinomycetemcomitans was isolated from $102(18.37 \%)$ individuals. The distribution of $A$. actinomycetemcomitans-positive individuals according to severity of periodontal disease, age, gender, smoking habits and geographic origins is presented in Table 1.

The occurrence of A. actinomycetemcomitans according to the diagnostic examination showed that out of 180 subjects with mild chronic periodontitis, $29(16.11 \%)$ were A. actinomycetemcomitans-positive. This bacterium was present in $42(17.42 \%)$ out of 241 subjects with moderate chronic periodontitis, while the high occurrence of $A$. actinomycetemcomitans was observed in severe chronic periodontitis [31 (23.13\%) out of 134 subjects (Graph 1)], although, with no statistically significant difference among groups.

The mean values of Plaque and Gingival Indices in the A. actinomycetemcomitans positive individuals are expressed in Table 2. This analysis revealed that no statistical difference was observed between both parameters according to severity of disease.

The 102 (mean age $32.94 \pm 11.70$ ) A. actino- 
Table 1 - Periodontal status of study population according to age, gender, smoking habits and geographic origins.

\begin{tabular}{c|c|c|c|c|c}
\hline \multicolumn{2}{c|}{ Clinical Parameter } & $\begin{array}{c}\text { Mild Mean } \\
\text { CAL } \geq 0.6 \text { to } 1.5 \mathrm{~mm}\end{array}$ & $\begin{array}{c}\text { Moderate Mean } \\
\text { CAL } \geq 1.6 \text { to } 2.4 \mathrm{~mm}\end{array}$ & $\begin{array}{c}\text { Severe Mean } \\
\text { CAL } \geq 2.5 \mathrm{~mm}\end{array}$ & Total \\
\hline \multicolumn{2}{c|}{ Number (\%) } & $\mathrm{N}=29(16.11 \%)$ & $\mathrm{N}=42(17.42 \%)$ & $\mathrm{N}=31(23.13 \%)$ & $\mathrm{N}=102(18.37 \%)$ \\
\hline \multirow{2}{*}{ Age (Mean \pm SD) } & $27.59 \pm 10.24$ & $33.48 \pm 10.93$ & $37.23 \pm 12.37$ & $32.94 \pm 11.70$ \\
\hline \multirow{2}{*}{ Gender } & Female & $19(65.10 \%)$ & $25(59.50 \%)$ & $15(48.40 \%)$ & $59(57.80 \%)$ \\
\cline { 2 - 7 } & Male & $10(34.90 \%)$ & $17(40.50 \%)$ & $16(51.60 \%)$ & $43(42.20 \%)$ \\
\hline \multirow{2}{*}{ Smokers } & Current & $5(17.30 \%)$ & $5(11.90 \%)$ & $8(25.80 \%)$ & $18(17.60 \%)$ \\
\cline { 2 - 7 } & Never & $24(82.7 \%)$ & $37(88.10 \%)$ & $23(74.20 \%)$ & $84(82.40 \%)$ \\
\hline \multicolumn{2}{c|}{ BS (\%) } & $13(44.80 \%)$ & $22(52.30 \%)$ & $18(58.10 \%)$ & $53(51.20 \%)$ \\
\hline \multicolumn{2}{c|}{ VP (\%) } & $16(55.20 \%)$ & $20(47.70 \%)$ & $13(41.90 \%)$ & $49(48.8 \%)$ \\
\hline
\end{tabular}

SD = standard deviation; BS = Baixada Santista; VP = Vale do Paraíba

Table 2 - Mean values of Plaque and Gingival Indices according to chronic periodontitis diagnosis.

\begin{tabular}{c|c|c}
\hline & $\begin{array}{c}\text { Plaque Index } \\
{[\text { Mean } \pm \text { SD (range)] }}\end{array}$ & $\begin{array}{c}\text { Gingival Index } \\
{[\text { Mean } \pm \text { SD (range)] }}\end{array}$ \\
\hline Mild Periodontitis & $0.40 \pm 1.16(0.04-0.76)$ & $0.69 \pm 0.18(0.00-1.00)$ \\
\hline Moderate Periodontitis & $0.51 \pm 0.30(0.00-1.00)$ & $0.71 \pm 1.16(0.00-1.00)$ \\
\hline Severe Periodontitis & $0.49 \pm 0.36(0.00-1.00)$ & $0.73 \pm 0.15(0.00-1.00)$ \\
\hline
\end{tabular}

$\mathrm{SD}=$ Standard Deviation

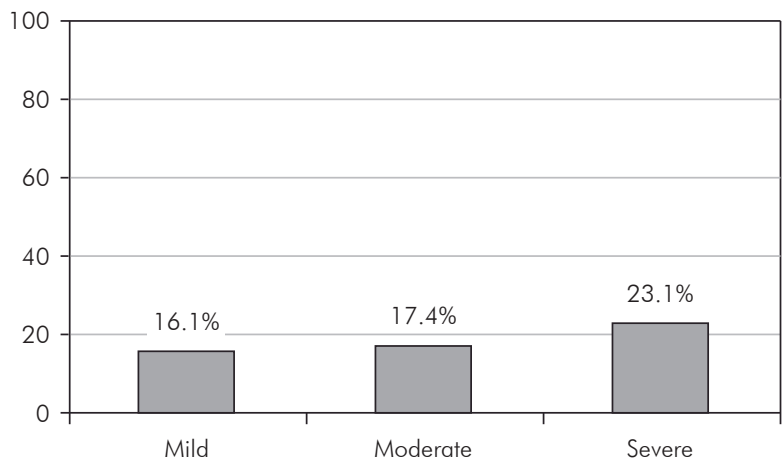

Graph 1 - Prevalence of A. actinomycetemcomitans-positive subjects according to severity of chronic periodontitis.

mycetemcomitans positive individuals were stratified in 3 different groups by age (until 30 years old; from 30 to 40 years of age and under 40 years old). Comparison of $A$. actinomycetemcomitans positive individuals among age groups is shown in Graph 2. When we compared the presence of A. actinomycetemcomitans according to age groups we verified a higher occurrence of this bacterium in the youngest population $(p<0.05)$. Moreover, when we took into consideration the occurrence of A. actinomy-

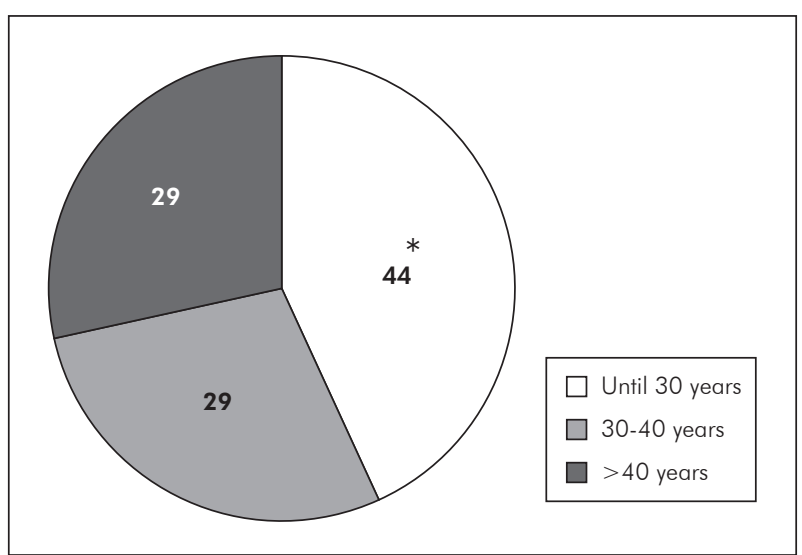

Graph 2 - Comparison of $A$. actinomycetemcomitans positive individuals between age groups. ${ }^{*} p<0.05$.

cetemcomitans positive individuals according to gender (Graph 3) a higher occurrence was observed in females $(p<0.05)$. On the other hand, we detected no statistical difference between BS and VL populations according to A. actinomycetemcomitans positive individuals (Graph 4). The Table 3 shows the relationship between $A$. actinomycetemcomitans positive individuals and age as well as gender, calculated by the odds ratio. 


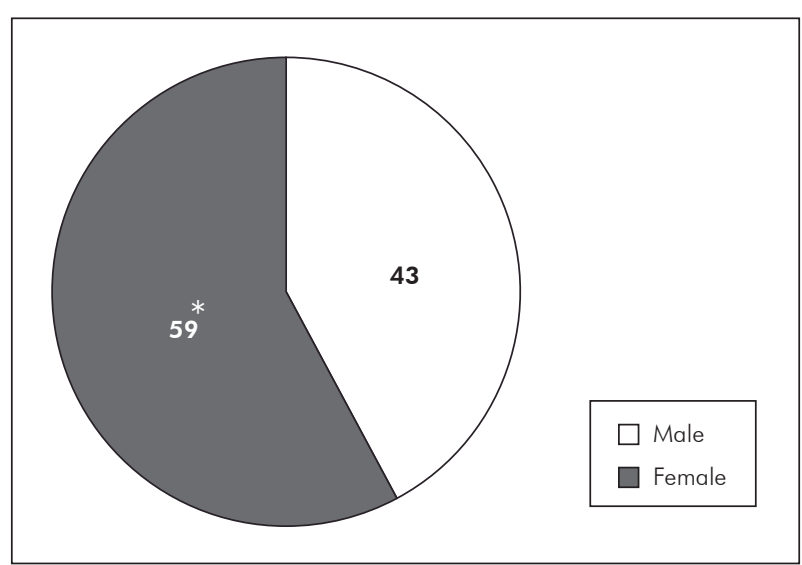

Graph 3 - Comparison of A. actinomycetemcomitans positive individuals by gender. ${ }^{*} p<0.05$.

Table 3 - Odds Ratio (OR) test according to age and gender.

\begin{tabular}{c|c|c|c|c}
\hline & OR & $p$ Value & Min Cl & Max Cl \\
\hline Age & 1.90 & 0.0409 & 1.0671 & 3.4172 \\
\hline Gender & 1.88 & 0.0357 & 1.0799 & 3.2820 \\
\hline
\end{tabular}

Min/max Cl - Minimum/Maximum Confidence Interval.

\section{Discussion}

Numerous studies have examined the prevalence of $A$. actinomycetemcomitans in populations in Europe and the United States. However, few studies have examined the prevalence of this bacterium in other parts of the world, particularly in chronic periodontitis subjects. Additionally, such variations in the global distribution of periodontopathic bacteria could be important in the epidemiology and the treatment of periodontal diseases. In view of the limited data available on the Brazilian distribution of A. actinomycetemcomitans in chronic periodontitis subjects ${ }^{5,7,22,23}$ and as this bacterium was also considered a true pathogen, we examined the occurrence of $A$. actinomycetemcomitans in Brazilian subjects with mild, moderate and severe chronic periodontitis.

We agree that in all forms of research, it would be ideal to test the entire population, but both groups here are just too large that would be impossible to include every individual in the present study. Taking this statement into consideration we made only a limited attempt to assure that this sample is an

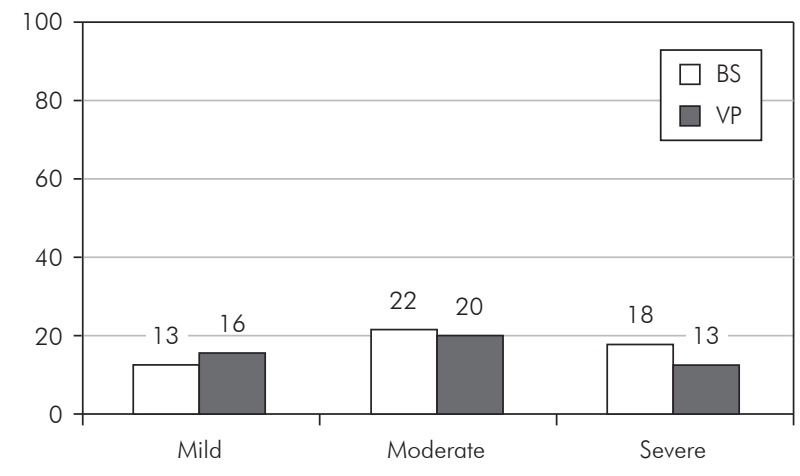

Graph 4 - Comparison of A. actinomycetemcomitans positive individuals between geographic origins.

accurate representation of "Baixada Santista" and "Vale do Paraíba" populations. The findings from our study would be considered less definite and with limited generalization and inference towards the entire population. Clearly, the results of our cross-sectional study have a low external validity.

Chronic periodontitis is a disease of multifactorial etiology influenced by several risk factors. ${ }^{24}$ These risk factors may influence age of onset, duration and severity of the disease. In our study, the general occurrence of $A$. actinomycetemcomitans was $18.37 \%$, varying from $16.11 \%$ for mild chronic periodontitis to $23.13 \%$ in severe chronic periodontitis patients. No significant difference was observed among different degrees of periodontal disease severity. The occurrence $(18.37 \%)$ observed in the present study is in agreement with two Latin- American studies conducted by Lafaurie et al. ${ }^{25}$ (2007) and Herrera et al. ${ }^{26}$ (2008) in Colombians chronic periodontitis (nearly 20\%). The study conducted by Yoshida et al. ${ }^{27}$ (2003) also found A. actinomycetemcomitans in $19.5 \%$ of 328 Japanese subjects with chronic periodontitis.

Recently, an interesting study was conducted by Vieira et al. ${ }^{23}$ (2009) in native Brazilians. The authors included 38 patients with periodontitis. Additionally, the study population have an average Plaque Index of 2.2 and Gingival Index of 1.8 besides an average Periodontal Pocket Depth of $5.8 \mathrm{~mm}$. They found a higher occurrence of A. actinomycetemcomitans $(34.21 \%)$ than our study, however, Vieira's population demonstrated more severity of periodontitis than did our subjects. 
The present investigation compared the occurrence of $A$. actinomycetemcomitans according to age. Our results showed a higher occurrence of this bacterium in the youngest group. Our data are consistent with the results of Meng et al. ${ }^{28}$ (2009). Their study investigated the prevalence of $A$. actinomycetemcomitans in Chinese chronic periodontitis patients and periodontally healthy adults. Their results showed that for chronic periodontitis patients, the prevalence of the bacterium in periodontitis sites $(33.62 \%)$ was significantly higher than in healthy sites $(0.90 \%)(\mathrm{p}<0.05)$; the occurrence showed a decreasing trend as patient age increased: highest in the 20 - to 35 -year-old group $(44.12 \%)$, followed by the 36 - to 55 -year-old group $(36.36 \%)$ and 56 - to 75 -year-old group $(22.73 \%)(\mathrm{p}<0.05)$. As the odds ratio shows the strength of association between a predictor and the outcome of interest, we investigated the relationship between A. actinomycetemcomitans positive individuals and age as well as gender. Despite the observed significant $p$ values for both age (0.0409) and gender (0.0357) variables, as the odds ratio values were between Minimum/ Maximum Confidence Interval [age (1.0671/3.4172) gender 1.0799/3.2820)], then, we were not able to consider these findings as a real odds ratio.

According to the proposed study design, we accepted that there was no hypothesis. The main aim was to describe, in both populations, the occurrence of Aggregatibacter actinomycetemcomitans in a subgroup within the population at a given timepoint with respect to an outcome of interest: level of chronic periodontitis. Then, obviously, we were

\section{References}

1. Zambon JJ. Periodontal diseases: microbial factors. Ann Periodontol. 1996 Nov;1(1):879-925.

2. Paju S, Carlson P, Jousimies-Somer H, Asikainen S. Heterogeneity of Actinobacillus actinomycetemcomitans strains in various human infections and relationships between serotype, genotype, and antimicrobial susceptibility. J Clin Microbiol. 2000 Jan;38(1):79-84.

3. Nonnenmacher C, Mutters R, de Jacoby LF. Microbiological characteristics of subgingival microbiota in adult periodontitis, localized juvenile periodontitis and rapidly progressive periodontitis subjects. Clin Microbiol Infect. 2001Apr;7(4):21317. limited to infer causality.

On the other hand, the present study provides some advantages. First, we could estimate the prevalence of the outcome of interest because our sampled population was taken from the two established populations: Baixada Santista and Vale do Paraíba. Secondly, the present study represented the first one performed in the population from Baixada Santista, offering to the local public health authorities the opportunity to understand in parts the etiology of periodontal disease and consequently to promote oral health care for the allocated population. Finally, we also considered that this study design was faster requiring only one time clinical and microbiological examinations and it was less expensive than some other study designs.

\section{Conclusion}

Authough the chronic periodontitis seems to be characterized by a mixed bacterial infection and not associated with any specific microorganism, the present study elucidated that subgingival pockets of our study population certainly harbored A. actinomycetemcomitans, and this bacterium seems to be inversely related to age, but related to female gender.

\section{Acknowledgement}

The study was supported by $\mathrm{CNPq}-\mathrm{The} \mathrm{Na}-$ tional Council for Scientific and Technological Development and FAPESP - The São Paulo Research Foundation.
4. Querido SM, Cortelli SC, Araújo MW, Cortelli JR. Clinical and microbial evaluation of dental scaling associated with subgingival minocycline in chronic periodontitis subjects. Braz Oral Res. 2004 Apr-Jun;18(2):110-5.

5. Cortelli JR, Cortelli SC, Jordan S, Haraszthy VI, Zambon JJ. Prevalence of periodontal pathogens in Brazilians with aggressive or chronic periodontitis. J Clin Periodont. 2005 Aug;32(8):860-66.

6. Leung WK, Ngai VK, Yau JY, Cheung BP, Tsang PW, Corbet EF. Characterization of Actinobacillus actinomycetemcomi- 
tans isolated from young Chinese aggressive periodontitis patients. J Periodontal Res. 2005 Mar;40(3):258-68.

7. Jardim Júnior EG, Bosco JM, Lopes AM, Landucci LF, Jardim EC, Carneiro SR. Occurrence of Actinobacillus actinomycetemcomitans in patients with chronic periodontitis, aggressive periodontitis, healthy subjects and children with gingivitis in two cities of the state of São Paulo, Brazil. J Appl Oral Sci. 2006 May-Jun;14(3):153-6.

8. Rylev M, Kilian M. Prevalence and distribuition of principal periodontal pathogens worldwide. J Clin Periodontol. 2008 Aug;35(8):346-61.

9. Faveri M, Figueiredo LC, Duarte PM, Mestnik MJ, Mayer MP, Feres M. Microbiological profile of untreated subjects with localized aggressive periodontitis. J Clin Periodontol. 2009 Sep;36(9):739-49.

10. Jervøe-Storm PM, Alahdab H, Koltzscher M, Fimmers R, Jepsen S. Quantification of periodontal pathogens by paper point sampling from the coronal and apical aspect of periodontal lesions by real-time PCR. Clin Oral Investig. 2009 Aug 20. [Epub ahead of print]

11. Wilson M, Henderson B. Virulence factors of Actinobacillus actinomycetemcomitans relevant to the pathogenesis of inflammatory periodontal diseases. FEMS Microbiol Rev. 1995 Apr; 17(4):365-79.

12. Zambon JJ, Slots J, Genco RJ. Serology of oral Actinobacillus actinomycetemcomitans and serotype distribution in human periodontal disease. Infect Immun. 1983 Jan;41(1):19-27.

13. Kaplan JB, Perry MB, Maclean LL, Furgang D, Wilson ME, Fine DH. Structural and genetic analyses of $\mathrm{O}$ polysaccharide from Actinobacillus actinomycetemcomitans serotype f. Infect Immun. 2001 Sep;69(9):5375-84.

14. Papapanou PN. Periodontal diseases: epidemiology. Ann Periodontol. 1996 Dec;1(1):1-36.

15. Brown LJ, Brunelle JA, Kingman A. Periodontal status in the United States, 1988-1991: prevalence, extent, and demographic variation. J Dent Res. 1996 Jan;75(1):672-83.

16. Haffajee AD, Socransky SS. Introduction to microbial aspects of periodontal biofilm communities, development and treatment. Periodontol 2000. 2006 Oct;42(1):7-12.

17. American Academy of Periodontology. Consensus report: section on epidemiology. Ann Periodontol 1996 Nov;1(1):2168.
18. Ainamo J, Bay I. Problems and proposals for recording gingivitis and plaque. Int Dent J. 1975 Apr;25(4):229-35.

19. Armitage GC, Wu Y, Wang HY, Sorrell J, di Giovine FS, Duff GW. Low prevalence of a periodontitis-associated interleukin1 composite genotype in individuals of Chinese heritage. J Periodontol. 2000 Feb;71(2):164-71.

20. Cortelli SC, Cortelli JR, Aquino DR, Holzhausen M, Franco $\mathrm{GC}$, Costa F de O, et al. Clinical status and detection of periodontopathogens and Streptococcus mutans in children with high levels of supragingival biofilm. Braz Oral Res. 2009 JulSep;23(3):313-8.

21. Cortelli JR, Aquino D, Cortelli SC, Fernandes CB, CarvalhoFilho J, Franco GCN, et al. Etiological analysis of initial colonization of periodontal pathogens in oral cavity. J Clin Microbiol. 2008 Apr;46(4):1322-9.

22. Colombo AP, Teles RP, Torres MC, Souto R, Rosalém WJ, Mendes MC, et al. Subgingival microbiota of Brazilian subjects with untreated chronic periodontitis. J Periodontol. 2002 Apr;73(4):360-9.

23. Vieira EM, Raslan SA, Wahasugui TC, Avila-Campos MJ, Marvulle V, Gaetti-Jardim Júnior E. Occurrence of Aggregatibacter actinomycetemcomitans in Brazilian indians from Umutina Reservation, Mato Grosso, Brazil. J Appl Oral Sci. 2009 Sep-Oct;17(5):440-5.

24. Pihlstrom B. Periodontal risk assessment, diagnosis and treatment planning. J Periodontol. 2001 Jan;25(1):37-58.

25. Lafaurie GI, Contreras A, Barón A, Botero J, Mayorga-Fayad I, Jaramillo A, et al. Demographic, clinical, and microbial aspects of chronic and aggressive periodontitis in Colombia: a multicenter study. J Periodontol. 2007 Apr;78(4):629-39.

26. Herrera D, Contreras A, Gamonal J, Oteo A, Jaramillo A, Silva $\mathrm{N}$, et al. Subgingival microbial profiles in chronic periodontitis patients from Chile, Colombia and Spain. J Clin Periodontol. 2008 Feb;35(2):106-13.

27. Yoshida Y, Suzuki N, Nakano Y, Shibuya K, Ogawa Y, Koga T. Distribution of Actinobacillus actinomycetemcomitans serotypes and Porphyromonas gingivalis in Japanese adults. Oral Microbiol Immunol. 2003 Jun;18(3):135-9.

28. Meng S, Zhao L, Yang H, Wu Y, Ouyang Y. Prevalence of Actinobacillus actinomycetemcomitans in Chinese chronic periodontitis patients and periodontally healthy adults. Quintessence Int. 2009 Jan;40(1):53-60. 